Asian J. Med. Biol. Res. 2020, 6 (3), 400-407; doi: 10.3329/ajmbr.v6i3.49787

\author{
Asian Journal of \\ Medical and Biological Research \\ ISSN 2411-4472 (Print) 2412-5571 (Online) \\ www.ebupress.com/journal/ajmbr
}

Article

\title{
Effects of feeding double strain spores as a probiotics with or without antibiotic growth promoter on broiler performance
}

\author{
Bibek Chandra Roy ${ }^{1 *}$ and Anguara Khatun ${ }^{2}$ \\ ${ }^{1}$ Central Poultry Farm, Mirpur, Dhaka, Bangladesh \\ ${ }^{2}$ Department of Poultry Science, Bangladesh Agricultural University, Mymensingh-2202, Bangladesh \\ *Corresponding author: Bibek Chandra Roy, Poultry Geneticist, Central Poultry Farm, Mirpur, Dhaka, \\ Bangladesh. Phone: +8801711-002238; E-mail: bibekdls@yahoo.com
}

Received: 15 July 2020/Accepted: 19 August 2020/ Published: 30 September 2020

\begin{abstract}
The objectives of the study were to investigate the effects of feeding probiotics supplemented diets with or without antibiotic growth promoter on growth performance, carcass characteristics and costeffectiveness of commercial broilers. A gable type open sided house was used for experimental purpose. Three hundred twenty Cobb-500 one- day-old straight run chicks were randomly distributed into four dietary groups having five replications. The number of birds in each replication was 16. Four diets were considered: diet 1: control; diet 2: antibiotic growth promoter (AGP) at a dose of $15 \mathrm{~g} / 100 \mathrm{~kg}$; diet 3: probiotics (PB) at a dose of $250 \mathrm{~g} / 100 \mathrm{~kg}$ and diet 4: AGP plus PB $(15 \mathrm{~g} / 100 \mathrm{~kg}+250 \mathrm{~g} / 100 \mathrm{~kg})$. Birds were vaccinated against common viral diseases as a part of disease prevention program. The records were kept of body weight, feed intake and mortality while weight gain, feed conversion ratio (FCR) and survivability were calculated. Both performance and carcass yield were statistically analyzed for interpretation. Broiler chicks that received PB showed significant improvement in performance $(P<0.01)$ over control with respect to body weight gain, FCR, carcass yield and cost-effectiveness. Feeding AGP alone had comparatively less weight gain, net profit and almost similar feed efficiency compared with $\mathrm{PB}$ and $\mathrm{AGP}+\mathrm{PB}$ groups but its performance was much better than that of control group. The PB fed group showed better meat yield traits. The PB alone group was also more cost effective over control. Feeding PB may be practiced in broiler diet as an alternative to AGP.
\end{abstract}

Keywords: probiotics; antibiotic; performance; carcass trait; net profit

\section{Introduction}

The term probiotics derived from Greek word "pro bios" which means "in favor of life" (Coppola and Turnes, 2004). According to the definition by FAO/WHO, probiotics are live microorganisms which when administered in adequate amounts confer a health benefit on the host (Fuller et al., 1989). Currently, probiotics seem to be good alternatives to the use of antibiotics as growth promoters (Tomasik and Tomasik, 2003), which have been used on poultry and livestock in an attempt to increase mean weight gain (Tannock et al., 1999). Probiotics are responsible for the production of vitamin B complex and digestive enzymes, and for stimulation of intestinal immunity, increasing protection against toxins produced by pathogenic microorganisms (Alexopoulos et al., 2004). Several microorganisms have been considered or used as probiotics including fungi particularly mushroom and yeast, bacteria and mixed cultures comprising of various microbes. In broiler nutrition, probiotic species such as Lactobacillus, Streptococcus, Bacillus, Bifidobacterium, Enterococcus, Aspergillus, Candida, and Saccharomyces are widely used to prevent poultry pathogens and diseases and improve broiler's growth performance (Timmerman et. al, 2006; Mountzouris et al., 2007; Awad et al., 2009). Bacteria are more commonly reported as probiotics than fungi. Two genera of bacteria are mostly reported including lactic acid bacteria of the genus Lactobacllus (Sato et. al., 2009; Taheri et. al., 2009) and Bifodobacteria (Patterson and Burkholder, 2003). A widely used probiotics strain, combination of Bacillus subtilis and Bacilluslicheniformis are considered one of the most health-boosting bacteria because they have demonstrated a positive effect in 
aiding nutrient digestion and absorption in the host's body (Scgarrd and Demark, 1990). The use of Bacillus subtilis and $B$. licheniformiss pores as a probiotics or a direct-fed microorganisms could be an alternative to adding medicine to feed in the prevention and treatment of broiler chickens' necrotic enteritis under commercial like conditions (Knap et al. 2010). Therefore, when used as a poultry growth promoter, these spores added to feed could enhance broiler chicken's digestibility and performance parameters by creating the favorable conditions for beneficial bacteria (Steiner et al., 2006). Since there have been a few investigations on combine effects of Bacillus subtilis and B. licheniformis in poultry, little information is available on its impact on nutrient metabolism and histological alterations to intestine in chickens so, to further prove the potential of these bacterial spore containing probiotics in improving broiler performance, this experiment investigated the effect of probiotics (combination of Bacillus subtilis and B. licheniformis) supplemented in feed with or without an antibiotic growth promoter. Keeping this view in mind, the present research work was undertaken to investigate the growth performance, carcass characteristics and cost-effectiveness of broilers fed probiotics supplemented diets with or without an antibiotic growth promoter.

\section{Materials and Methods}

\subsection{Experimental site, birds' diet and management}

The experiment was conducted at Bangladesh Agricultural University Poultry Farm, Mymensingh. The duration of the research work was 35 days. A total of 320 one day-old straight run Cobb-500 commercial broiler chicks were considered for this research work. The experimental broiler chicks were equally and randomly divided and distributed into four dietary groups and each group was replicated to five subgroups. Corn-soya based diet was supplied. The broiler diet was formulated for two phases (starter and grower). Starter diet was provided from $1^{\text {st }}$ day to $21^{\text {st }}$ days and grower diet was provided from $22^{\text {nd }}$ day to $35^{\text {th }}$ days. Both types of diets were supplied in mash form. The nutrient requirements (ME, CP, CF, EE, Ca, P, Lysine and Methionine) were satisfied as per requirement as recommended for Cobb-500 broiler strain diet. The first group of chicks were maintained control diet whereas, second, third and fourth group of chicks received control diet with AGP, control diet with probiotics and control diet with AGP plus probiotics respectively. The ingredient and nutrient composition of the basal diet is presented in Table 1and 2. The area of the room was $400 \mathrm{sq} . \mathrm{ft}$. The floor space allowed for each bird was 1 sq. ft. to ensure comfort of the birds. The room was partitioned by using wire net and bamboo materials. Fresh and dry rice husk was used as litter materials at a depth of about $5 \mathrm{~cm}$. The broiler was exposed to a continuous lighting of 23 hours and a dark period of 1 hour in each 24 hours of photoperiod. One round tube feeder and one round drinker were provided in each pen. All birds were vaccinated against infectious bronchitis and Newcastle disease by MA5+Clone30 on day 5. On day 10, vaccination was done against IBD and booster dose was performed on $\mathrm{d} 17$ by GM97, whereas the vaccination with the booster dose of Newcastle disease was done by Clone30 at day 21. Vaccines were collected from Intervet BV (Netherlands), Hipra (Spain) and administered according to manufacturers' recommendation. A strict biosecurity was maintained throughout the experimental period.

\subsection{Experimental sample}

\subsubsection{Antibiotic growth promoter (AGP)}

The trade name of antibiotic growth promoter used in the experiment was "Lincoplex" containing 2.2\% Lincomycin and manufactured by an Indian Company named "Starvet". This product was imported in Bangladesh by "Century Agro. Co. Ltd."

\subsubsection{Double strain probiotics- (A combination of Bacillus subtilis and Bacillus licheniformis)}

Double strain probiotics has been manufactured by one of the Korean companies named "Shinil Biogen Company Limited." and imported in Bangladesh by "Pharma and Firm Company Limited." Dhaka, Bangladesh. This probiotics contains Bacillus subtilis $\mathrm{CH} 201\left(4 \times 10^{10} \mathrm{CFU} / \mathrm{g}\right)$ and Bacillus licheniformis $\left(4 \times 10^{10} \mathrm{CFU} / \mathrm{g}\right)$. According to manufacturer, dose of the product for broiler is $250 \mathrm{~g} / 100 \mathrm{~kg}$ feed.

\subsection{Processing of broilers}

At the end of the trial, one male and one female broiler having near to pen average weight were taken from each pen for recording meat yield parameters. The birds were killed and allowed to bleed for 2 minutes and immersed in hot water $\left(51-55^{\circ} \mathrm{C}\right)$ for 120 seconds in order to loose the feathers. The feathers were removed by hand pinning. This was done manually. Then head, shank, viscera, giblet (heart, liver and gizzard) and abdominal fat were removed for determination of meat yield parameters. Dressed broilers were cut into different parts such as 
breast, thigh, drumstick, wing and back. Finally, every cut-up part was weighed and recorded for male and female broiler of all replications.

\subsection{Methods of cost benefit analysis}

Cost of production was calculated based on some specific items such as chicks, feed, vaccine, test ingredients and casual labor. Cost of heads was widely varied due to fluctuating market price. The total production cost per bird and per $\mathrm{kg}$ bird was calculated. The additional cost incurred for test ingredients was also taken into consideration for calculating cost benefit. The profit or loss was calculated by deducting the production cost per $\mathrm{kg}$ broiler and market price of per kg broiler.

\subsection{Data collection}

All data of body weight, feed consumption, feed conversion ratio and survivability were recorded on days 7,14 , 21, 28 and 35. At the end of the trial, carcass measurements data were also collected. During the experimental period, the temperature and relative humidity of the experimental house were recorded four times in a day (6.00 AM, 2.00 PM, 6.00 PM, 11.00 PM) with the help of an automatic thermo-hygrometer. At the end of the experiment the dressing percentage of the broiler was calculated as the dressed weight divided by final body weight of the broiler.

\subsection{Data analysis}

Data of body weight, body weight gain, feed consumption, feed conversion ratio (FCR), livability and edible meat characteristics of male and female broilers were subjected to analysis of variance (ANOVA) in a completely randomized design (CRD) employing SAS (2008, version 9.1) statistical computer package programme.

\section{Results}

\subsection{Growth performance}

Productive performance of broiler receiving feed supplemented with probiotics or antibiotic or their combination are shown in Figure. At the end of 35 days of age, the highest FLW (2014.50g/b) was found in broilers fed with both antibiotic growth promoter and probiotics (AGP+PB). This was followed by broiler belonging to probiotics $(1913.06 \mathrm{~g} / \mathrm{b})$, antibiotic $(1848.25 \mathrm{~g} / \mathrm{b})$ and control group $(1707.20 \mathrm{~g} / \mathrm{b})$ respectively. However, broiler receiving either probiotics or antibiotic or both weighed significantly higher than that of control $(P<0.01)$. The difference with regard to live weight and live weight gain among AGP, PB and AGP + PB were also significant $(P<0.01)$ (Figure 1). The average FI pattern of the broilers of different treatment groups which was differed significantly $(P<0.01)$. Highest amount of feed was consumed by AGP+PB fed group and lowest amount of feed was consumed by AGP fed group. Both AGP and PB containing groups consumed similar amounts of feed and there was no significant difference between them but they are significantly $(P<0.01)$ differed from control and AGP+PB supplemented diet (Figure 2). Differences in cumulative feed conversion ratio of broiler of different dietary groups differed significantly $(P<0.01)$. The lowest value was obtained for birds that received probiotics (Figure 3). PB, AGP+PB and AGP supplemented groups showed almost similar but improved efficiency that differed from control group $(P<0.01)$. AGP, PB and AGP+PB receiving groups had $100 \%$ survivability while the survivability of the control group was $97.33 \%$.

\subsection{Edible meat yield characteristics}

Meat yield data are presented in Table 3. The analyzed data in the table indicates that the treatments had no significant effect $(P>0.05)$ on live weight, dressing percentage, thigh, wing and heart weight of the experimental birds. On the other hand, highly significant $(P<0.01)$ differences were obtained in breast meat, abdominal fat content and head weight among different treatments. Highest and lowest breast meat weight was recorded in PB and control group respectively. There was a tendency of increased breast meat content in both PB and AGP+PB groups which had highly significant $(P<0.01)$ effect compared to control group. Higher abdominal fat was determined in control group while lower was in PB group. Also, significant differences $(P<0.05)$ were found on liver, drumstick, and gizzard weight among the dietary groups.

\subsection{Cost benefit analysis}

The cost benefit analysis of feeding AGP and PB is shown in Table 4. The additional cost was incurred 0.37, 0.114 and 0.484 BDT (Bangladeshi Taka) for AGP, PB and AGP+PB fed group respectively. For per bird, total cost of production was maximum (@BDT 173.19) in AGP+PB group and minimum (@BDT 164.27) in AGP 
supplemented group. The total cost of production for per kg body weight was highest (@ BDT 97.54) in control group and lowest (@ BDT 85.75) in AGP+PB group. In terms of per bird and per kg body weight, the profit was maximum in $\mathrm{AGP}+\mathrm{PB}$ treated group. The supplementation of $\mathrm{AGP}+\mathrm{PB}$ fed group was more profitable over the control group.

Table 1. Ingredient composition of broiler starter and grower ration.

\begin{tabular}{lllllllll}
\hline Ingredients (\%) & \multicolumn{4}{c}{ Starter diet (0-21d) } & \multicolumn{3}{c}{ Grower diet (22-35d) } \\
\cline { 2 - 9 } & Control & AGP & PB & AGP+PB & Control & AGP & PB & AGP+PB \\
\hline Corn & 51.16 & 51.16 & 51.16 & 51.16 & 61.45 & 61.45 & 61.45 & 61.45 \\
SM 44\% & 41.71 & 41.71 & 41.71 & 41.71 & 31.63 & 31.63 & 31.63 & 31.63 \\
Soya oil & 3.38 & 3.38 & 3.38 & 3.38 & 3.10 & 3.10 & 3.10 & 3.10 \\
DCP & 1.63 & 1.63 & 1.63 & 1.63 & 1.725 & 1.725 & 1.725 & 1.725 \\
CaCO & 0.953 & 0.953 & 0.953 & 0.953 & 0.94 & 0.94 & 0.94 & 0.94 \\
NaCl & 0.273 & 0.273 & 0.273 & 0.273 & 0.27 & 0.27 & 0.27 & 0.27 \\
NaHCO & 0.23 & 0.23 & 0.23 & 0.23 & 0.23 & 0.23 & 0.23 & 0.23 \\
DL-Met. & 0.305 & 0.305 & 0.305 & 0.305 & 0.25 & 0.25 & 0.25 & 0.25 \\
L-Lysine & 0.05 & 0.05 & 0.05 & 0.05 & 0.11 & 0.11 & 0.11 & 0.11 \\
L-threonine & 0.03 & 0.03 & 0.03 & 0.03 & 0.04 & 0.04 & 0.04 & 0.04 \\
Premix & 0.25 & 0.25 & 0.25 & 0.25 & 0.25 & 0.25 & 0.25 & 0.25 \\
AGP & - & 0.015 & - & 0.015 & - & 0.015 & - & 0.015 \\
PB & - & - & 0.25 & 0.25 & - & - & 0.25 & 0.25 \\
\hline
\end{tabular}

$\mathrm{SM}=$ soybean meal, $\mathrm{CaCo} 3=$ calcium carbonate, Met=methionine, $\mathrm{AGP}=$ antibiotic growth promoter, $\mathrm{PB}=$ probiotics, $\mathrm{AGP}+\mathrm{PB}=$ antibiotic growth promoter+probiotics. $\mathrm{DCP}=\mathrm{Di}$ Calcium Phosphate, $\mathrm{NaCl}=$ Sodium $\mathrm{Chloride}, \mathrm{NaHCO}_{3}=$ Sodium bi Carbonate, AGP= Antibiotic growth promoter.

Table 2. Nutrient composition of diet.

\begin{tabular}{lll}
\hline Parameter & Starter diet (0-21days) & Grower diet (22-35days) \\
\hline ME (kcal/kg) & 3000 & 3100 \\
Crude protein (\%) & 23.43 & 20.38 \\
Ether extract (\%) & 2.70 & 2.89 \\
Crude fiber (\%) & 2.66 & 2.55 \\
Lysine (\%) & 1.24 & 1.06 \\
Methionine (\%) & 0.32 & 0.291 \\
Met+Cystine (\%) & 0.64 & 0.57 \\
Calcium (\%) & 1.05 & 0.90 \\
Available Phosphorus (\%) & 0.50 & 0.45 \\
\hline
\end{tabular}

$\mathrm{ME}=$ metabolizable energy, $\mathrm{kcal}=$ kilo calorie, $\mathrm{kg}=$ kilogram, $\%=$ percentage, $\mathrm{Met}=$ methionine

Table 3. Some edible meat yield characteristics of broilers fed on probiotic with or without antibiotic growth promoter (0-35 days).

\begin{tabular}{|c|c|c|c|c|c|}
\hline \multirow[t]{2}{*}{ Variable } & \multicolumn{4}{|c|}{ Dietary treatments } & \multirow{2}{*}{$\begin{array}{l}\text { Level of } \\
\text { significance }\end{array}$} \\
\hline & Control & AGP & PB & AGP+PB & \\
\hline $\mathrm{LW}(\mathrm{g} / \mathrm{b})$ & $1990 \pm 29.60$ & $2061 \pm 49.20$ & $2113 \pm 61.70$ & $2144 \pm 74.74$ & NS \\
\hline $\mathrm{DP} \%$ & $68.39 \pm 1.15$ & $69.77 \pm 0.44$ & $69.47 \pm 0.56$ & $68.56 \pm 0.61$ & NS \\
\hline Thigh (g) & $141 \pm 2.92$ & $147 \pm 4.06$ & $148 \pm 3.53$ & $149.2 \pm 4.07$ & NS \\
\hline Drumstick (g) & $96^{\mathrm{b}} \pm 1.87$ & $96.80^{\mathrm{ab}} \pm 2.60$ & $107.0^{\mathrm{a}} \pm 4.64$ & $102^{\mathrm{ab}} \pm 3.74$ & * \\
\hline Breast meat $(\mathrm{g})$ & $403.0^{\mathrm{c}} \pm 4.36$ & $491.0^{\mathrm{b}} \pm 10.17$ & $532.0^{\mathrm{a}} \pm 14.70$ & $497.0^{\mathrm{ab}} \pm 16.48$ & $* *$ \\
\hline Wing meat $(\mathrm{g})$ & $94.00 \pm 1.87$ & $95.2 \pm 6.04$ & $95.2 \pm 6.04$ & $98 \pm 3.32$ & NS \\
\hline Head $(g)$ & $25^{\mathrm{bc}} \pm 0.00$ & $23.8^{\mathrm{c}} \pm 1.07$ & $32.0^{\mathrm{a}} \pm 1.08$ & $27.2^{\mathrm{b}} \pm 0.97$ & $* *$ \\
\hline Liver $(g)$ & $45^{\mathrm{b}} \pm 1.58$ & $49.4^{\mathrm{ab}} \pm 2.16$ & $48.6^{\mathrm{ab}} \pm 0.98$ & $51^{\mathrm{a}} \pm 1.87$ & $*$ \\
\hline Gizzard $(\mathrm{g})$ & $35^{\mathrm{b}} \pm 1.58$ & $35.6^{\mathrm{ab}} \pm 2.42$ & $35.4^{\mathrm{ab}} \pm 1.29$ & $41^{\mathrm{a}} \pm 1.87$ & * \\
\hline Heart(g) & $9.4 \pm 0.87$ & $11.2 \pm 0.80$ & $12 \pm 1.22$ & $12 \pm 0.63$ & NS \\
\hline $\mathrm{AF}(\mathrm{g})$ & $29.2^{\mathrm{a}} \pm 1.66$ & $10.6^{\mathrm{b}} \pm 1.33$ & $3.6^{\mathrm{c}} \pm 2.23$ & $5.2^{\mathrm{bc}} \pm 2.15$ & $* *$ \\
\hline
\end{tabular}

$\mathrm{LW}=$ live weight, $\mathrm{DP}=$ dressing percentage, $\mathrm{AF}=$ abdominal fat, $\mathrm{AGP}=$ antibiotic growth promoter, $\mathrm{PB}=$ probiotics, $\mathrm{g} / \mathrm{b}=\mathrm{gram}$ per bird; g=gram, NS= Non-significant, \pm Standard Error Mean (SEM). a,b,c Means bearing dissimilar superscript in a row differ significantly, $* *=(P<0.01), *=(P<0.05)$. 
Table 4. Cost of production and profit in different dietary treatment groups of broilers.

\begin{tabular}{lllll}
\hline Items & Control & AGP & PB & AGP+PB \\
\hline (a) Feed cost (Tk./bird) & 102.5 & 100.16 & 101.91 & 108.71 \\
(b) AGP and PB cost" (Tk./bird) & --- & 0.114 & 0.37 & 0.484 \\
(c) Chick cost (Tk./bird) & 32.0 & 32.0 & 32.0 & 32.0 \\
(d) Other costs (vaccines, litter, disinfectants, & 32.0 & 32.0 & 32.0 & 32.0 \\
transport, labor etc.) (Tk./bird) & 166.50 & 164.27 & 166.28 & 173.19 \\
(e) Total cost (Tk./bird) (a+b+c+d) & 97.54 & 88.83 & 86.73 & 85.75 \\
(f) Total cost (Tk./kg body weight) & 247.52 & 267.96 & 277.39 & 292.03 \\
(g) Sale price (@ BDT 120/kg) & 38.34 & 57.486 & 63.28 & 68.486 \\
(h) Profit (Tk./bird) (g-e) & 22.47 & 31.11 & 33.08 & 34.00 \\
(i) Profit (Tk./kg) & -- & 19.15 & 24.94 & 30.15 \\
(j) Profit over control (Tk./bird) & -- & 8.64 & 10.61 & 11.53 \\
(j) Profit over control (Tk./kg) & & & \\
\hline
\end{tabular}

*AGP @ BDTTk.760/kg, probiotics @ BDT Tk. 185/kg, AGP=antibiotic growth promoter, PB= probiotics, $\mathrm{AGP}+\mathrm{PB}=$ antibiotic growth promoter + probiotic. $@=$ at the rate, Tk.=Taka, g=gram, kg=kilogram.

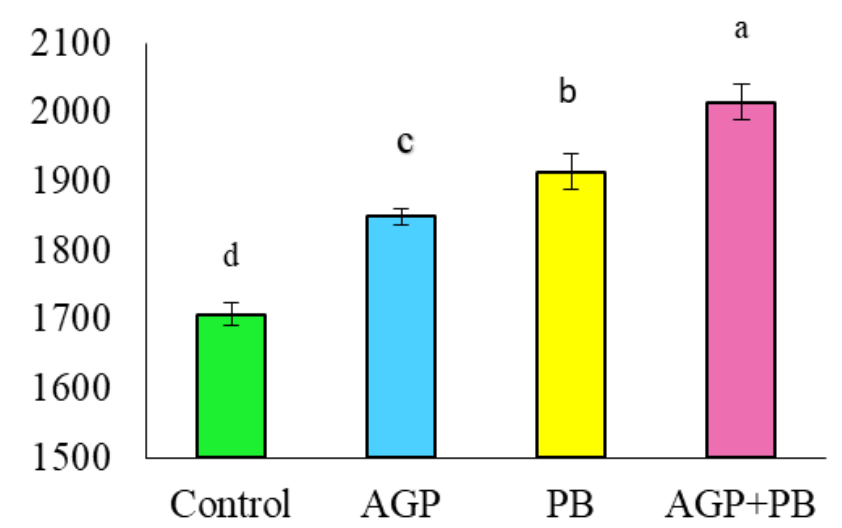

Figure 1. Final body weight of different dietary treatments.

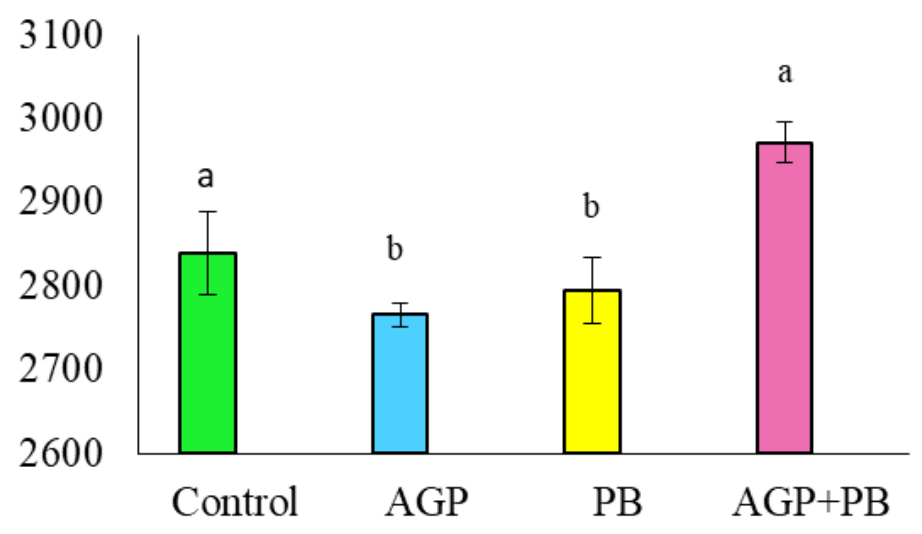

Figure 2. Feed consumption patterns of different treatments. 


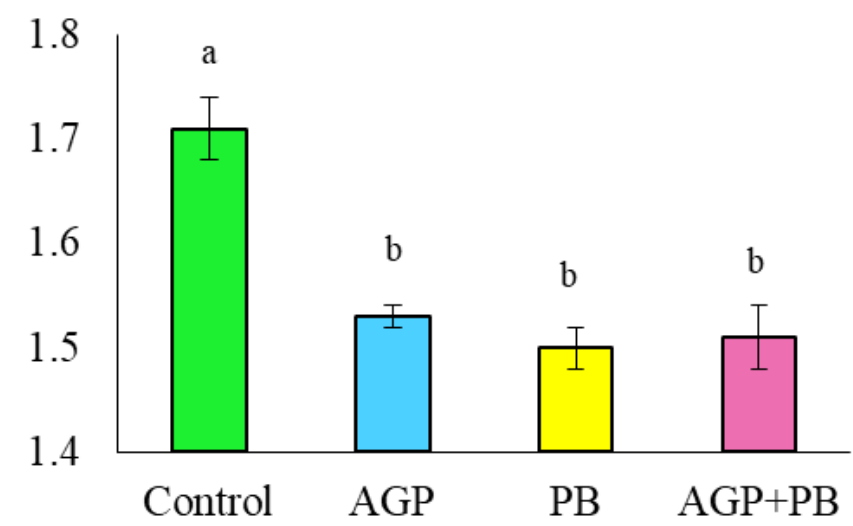

Figure 3. Feed conversion efficiency patterns of different treatments.

\section{Discussion}

The results obtained in this study are consistence with the findings of Bai et al. (2013). They compared the probiotics treated group with a control, an antibiotic and(antibiotic+ probiotics) treated group and found that antibiotic, probiotics and their combination improved average body weight in broilers during growing period (21-42days) compared with control. Other author Sabatkova et al. (2008) compared the efficacy of Avilamycin (AGP) and probiotics (Bacillus subtilis and B. licheniformis) to investigate the performance and slaughter yields. They finally reported that the supplementation of probiotics improved $4-5 \%$ weight gain $(P<0.01)$. Ahmad and Taghi (2006) also found that body weight gain of broiler, fed supplemented with probiotics (Bacillus subtilis and B. licheniformis) were significantly higher during the grower phase (21-42 days) than broiler fed the control diets. Not only that, the finding of this trial is also agreed with Salim et al. (2013); Shim et al. (2012); Ashayerizadeh et al. (2009); O'Dea et al. (2006).They also reported that supplementation of probiotics in broiler feed improved body weight and body weight gain significantly. In this study, both the live weight and live weight gain of the broiler of both $\mathrm{PB}$ and AGP+PB groups are very close to the Cobb500 commercial broiler's productive performance (Cobb 500 Management Guide, 2010). Comparatively lower feed consumption in probiotics supplemented group was in agreement with the results of Shim et al. (2012). They found that birds fed $10 \mathrm{mg} / \mathrm{kg}$ avilamycin consumed more $(p<0.05)$ feed during the finisher and overall periods than birds fed diets containing probiotics without avilamycin while others have found non-significant variation in feed intake between control and probiotics group (Faria et al. 2009; Rada et al., 2013). But the result was consistence with Eseceli and Demir (2010) and Erdogan (2007). They also reported that supplementation of probiotics decreased feed intake significantly $(P<0.05)$ compared to control group. In the present study feed intake of probiotics treated group was significantly lower $(P<0.01)$ than control and AGP+PB treated groups. The significant effect of probiotic on feed conversion ratio (FCR) of broiler was in close agreement with Shim et al. (2012); Ashayerizadeh et al. (2009); Sabatkova et al. (2008) and O'Dea et al. (2006). They found that supplementing with Bacillus subtilis and B. licheniformis improved feed conversion efficiency in broiler. Salim et al. (2013) also reported the lowest feed conversion ratio (FCR) with probiotic compared to antibiotic and control group respectively. This result was almost similar to the present study. Positive effect on livability was observed in this study by feeding probiotic to broiler which was consistence with the observation of Knap et al. (2011) and Zhang RenYi (2010). They also found that feeding probiotics (Bacillus spp.) supplemented diet effectively enhance the resistance of broiler and protect them against the negative growth effects and mortality. But Faria et al. (2009) and Eseceli and Demir (2010) revealed that there was no statistically significant difference $(P>0.01)$ in the livability of birds reared with or without adding probiotics in diet.

The results of present study clearly indicate the effect of dietary probiotics towards some important meat yield characteristics of broiler. This result was particularly similar to the result of Molnar et al. (2013) who reported that Bacillus spp. supplemented group had significantly higher $(P<0.05)$ breast yield and lower thigh meat yield than the control group where the breast weight of this experiment was lowest for control and highest for PB supplemented group respectively. Luiz et al. (2012) compared the efficacy of antibiotic with probiotics in meat yield characteristics of broiler and finally reported that probiotics group have lower abdominal fat content compared to antibiotic and control group respectively which is supported recent findings. The result of this 
study was also particularly consistent with the findings of Xiaolu et al. (2012), who reported that the supplementation of Bacillus licheniformis resulted in increased protein and free amino acid contents, and decreased fat content in chicken breast fillet $(P<0.05)$. Moreira et al. (2001) found no significant difference in carcass yield between birds that were fed probiotic and control diet. However, the result of this study agreed well with the findings of Lei et al. (2013) and Sabatkova et al. (2008).

The present study clearly indicates that feeding of AGP, PB and their combination had beneficial effect on the profitability of broiler. The combination of AGP+PB provided highest profit which is almost similar to $\mathrm{PB}$ group but higher than the control and AGP group. This result was particularly similar to the results of Roy et al (2013) who reported that feeding probiotics to broiler was either similar or more profitable than combination of AGP+PB while better than AGP alone.

\section{Conclusions}

The AGP+PB and PB containing diet improved growth performance over AGP and control group.The PB containing diet improved breast meat, drumstick meat and reduced abdominal fat percentage whereas, control group had highest abdominal fat percentage. The profit per kg of body weight was higher in PB group compared to control.

\section{Acknowledgements}

The authors are very much grateful Mr. Shakhawat Hossain, Head of Marketing, Century Agro Limited for providing AGP. The authors are also thankful to Department of Poultry Science, Bangladesh Agricultural University, Mymensingh-2202.

\section{Conflict of interest}

None to declare.

\section{References}

Ahmad K and G Taghi, 2006. Effect of probiotic on performance and immune competence in broiler chicks. J. Poult. Sci., 43: 296-300.

Alexopoulos IL, A Georgoulakis, SK Tzivara, A Kritas, SC Siochu and Kyriakis, 2004. Field evaluation of the efficacy of a probiotic containing Bacillus licheniformis and Bacillus subtilis spores, on the health status and performance of sows and their litters. J. Anim. Physio. Nutri., 88: 381-392.

Ashayerizadeh A, N Dabiri, O Ashayrizadeh, KH Mizadeh, H Roshanfekr and M Mamooee, 2009. Effects of dietary antibiotic, probiotic and prebiotic as growth promoter on growth performance, carcass characteristics and hematological indices of broiler chickens. Pak. J. Biol. Sci., 12: 52-57.

Awad WA, Ghareeb K., Raheem AS and Böhm J, 2009. Effects of dietary inclusion of probiotic. J. Poult. Sci., 88: 49-56.

Bai SP, AM Wu, XM Ding, Y Lei, J Bai and JS Chio, 2013. Effects of probiotic-supplemented diets on growth performance and intestinal immune characteristics of broiler chickens. J. Poult. Sci., 92: 633-670.

Cobb 500 Management Guide. Revised 2010. cobb.vantress.com

Coppola MM and CG Turns, 2004. Probioticos e resposta immune. Ciencia Rural., 34: 1297-1303.

Erdogan Z, 2007. The use of antibiotic and probiotic in broiler diets. Lalaham-Hayvancilik-ArastirmaenstitusuDergisi., 39: 37-69.

Eseceli $\mathrm{H}$ and E Demir, 2010. The effect of Bio-MosReg. Mannan oligosaccharide and antibiotic growth promoter on performance of broiler. J. Anim.Vet. Adv., 9: 392-395.

Faria DE, APF Henrique and R Franzolin, 2009. Alternatives to the use of antibiotic growth promoter for broiler chickens. Cienc. Anim. Bras., 10: 18-28.

Fuller R, 1989. Probiotics in man and animals. J. App. Biotechnol., 66: 365-378.

Knap I, B Lund, AB Kehle, C Hofacre and G Mathis, 2010. Bacillus licheniformis prevents necrotic enteritis in broiler chickens. J. Ameri. Asso.Avi. Dis., 54: 931-935.

Lei K, YL Li, DY Yu and WF Li, 2013. Influence of dietary inclusion of Bacillus licheniformis on laying performance, egg quality, antioxidant enzyme activityand intestinal barrier function of laying hen. J. Poult. Sci., 92: 2389-2395.

Luiz G, A Aristides, A Oba and M Shimokomaki, 2012. The effects of biotic additives on growth performance and meat qualities of broiler. Int. J. Poult. Sci., 11: 599-604. 
Molnar AK, B Podmaniczky, P Kurti, I Tenk, GY Virag and ZS Szabo, 2013. Effect of different concentration of Bacillus subtilis on growth performance, carcass quality, gut microflora and immune response of broiler chickens. J. Bri. Poult. Sci., 52: 658-665.

Moreira J, AA Mendes, EA Garcia, RG Garcia, ICL Almeida JR and JGC, 2001. Efeito do uso do probióticosobre o desempenho e rendimento de carcaçaemfrangos de corte. In: XXXVIII Reunião Anual da SBZ, Piracicaba. Anais. Piracicaba, 852-854.

Mountzouris KC, P Tsirtsikos, E Kalamara, S Nitsch, G Schatzmayr and K Fegeros, 2007. Evaluation of the efficacy of a probiotic containing lactobacillus, bacillus, bifidobacterium, enterococcus, and pediococcus strains in promoting broiler performance and modulating cecal microflora composition and metabolic activities. J. Poult. Sci., 86: 309-317.

O'Dea E, GM Fasenko, GE Allison, DR Korver and LL Guan, 2006. Investigating the effects of commercial probiotics on broiler chick quality and production efficiency. J. Poult. Sci., 685: 1855-1863.

Patterson JA and KM Burkholder, 2003. Application of prebiotics and probiotics in poultry production. J. Poult. Sci., 82: 627-631.

Rada, M Foltyn, M Lichovnikova and A Musilova, 2013.Effects of protease supplementation of low protein diets on growth parameters and carcass characteristics. Mendel Net., 268-272.

Roy BC and SD Chowdhury, 2013. Effect of dietary probiotic and antibiotic growth promoter either alone or in combination on the growth performance of broilers during summer.Proceedings of the $8^{\text {th }}$ International Poultry Show and Seminar, 28 February-02 March 2013, Dhaka, Bangladesh. Edited by: World's Poultry Science Association Bangladesh Branch, pp. 153-158.

Sabatkova J, I Kumprecht and P Zobac, 2008. The probiotic Bio plus 2B as an alternative of antibiotic in diets for broiler chickens. Acta. Vet. Brno., 77: 569-574.

Salim HM, KH Kang, N Akter, DW Kim, JC Na, HB Jong, HC Choi and WK Kim, 2013. Supplementation of direct-fed microbials as an alternative to antibiotic on growth performance, immune response, cecal microbial population, and ileal morphology of broiler chickens. J. Poult. Sci., 92: 2084-2090.

SAS, 2009. Statistical Package. SAS Institute. Version 9.1. Available via http://support.sas.com_(Accessed 1 December 2018).

Sato K, K Takahashi, M Tohno, Y Miura, T Kamada, I Ikegami and I Kitazawa, 2009. Immunomodulation in gut-associated lymphoid tissue of neonatal chicks by immunobiotic diets. J. Poult. Sci., 88: 2532-2538.

Scgaard DH and T Suhr-Jessen, 1990. Microbials for feed beyond lactic acid bacteria.Feed Int., 11: 32-38.

Shim YH, SL Ingali, JS Kim, DK Seo, SC Lee and IK Kwon, 2012. A multi-microbe probiotic formulation processed at low and high drying temperatures: effects on growth performance, nutrient retention and cecal microbiology of broilers. J. Bri. Poult. Sci., 53: 482-490.

Steiner T, 2006. Managing Gut Health: Natural Growth Promoters as a Key to Animal Performance. Nottingham University Press, Nottingham, UK. 2006.

Taherpour K, H Moravej, M Shivazad, M Adibmoradi and B Yakhchali, 2009. Effects of dietary probiotic, prebiotic and butyric acid glycerides on performance and serum composition in broiler chickens. Afri. J. Biotechnol., 8: 2329-2334.

Tannock, GW, 1999. What we know and need to know. J. Adv. Biotechnol., 17: 691-693.

Timmerman HM, Veldman A, Van Den Elsen E, Rombouts FM and Beynen CA, 2006. Mortality and growth performance of broilers given drinking water supplemented with chicken-specific probiotics. J. Poult. Sci., 85: 1383-1388.

Tomasik PJ and Tomasik P, 2003. A review on probiotics and prebiotics. Cer. Chem., 80:113-117.

Xiaolu L, Yan H, Lv, X, Qianqian K, Zhang H and Jiye K, 2012. Growth performance and meat quality of broiler chickens supplemented with Bacillus licheniformisin drinking water. Asian-Australas. J. Anim. Sci. 25: 682-689.

Zhang ren Yi, 2010. A study of effects and mechanisms of Bacillus licheniformis on performance in broiler. Anim. Physio. Anim. Nutri., 95: 523-532. 